\title{
- The fine line between success and failure in scleroderma lung fibrosis trials
}

Scleroderma (systemic sclerosis; SSc) is a complex multisystem disease with high morbidity and mortality. Pulmonary complications are a major cause of death in SSc; however, there are few effective treatments of lung fibrosis (interstitial lung disease; ILD). The evidence base for the current approach of using broad-spectrum immunosuppression with mycophenolate mofetil or cyclophosphamide in SSc-ILD has been supported by three prospective randomized trials, but in general these trials are difficult to design and execute. This is primarily due to SSc-ILD being a rare disease with a relatively slow rate of progression compared with idiopathic pulmonary fibrosis (IPF). This slower progression is reassuring for patients, but makes it more challenging to adequately power clinical trials. However, despite these challenges, it is important to undertake studies given the substantial impact of pulmonary fibrosis on morbidity and mortality in SSc, and a number of trials are underway.

Current trials need to proceed in the landscape of previous studies and should incorporate lessons learned from earlier success or failure. Prospective randomized clinical trials of patients with SSc-ILD have been challenging, but even studies that are unequivocally negative, such as BUILD-2 (1), have provided valuable prospective data on the natural history of SSC-ILD and the measurement variability of common clinical trial endpoints. The most recent SSc-ILD trial is SLS2 that compared oral cyclophosphamide to mycophenolate mofetil in 126 patients with SSc-ILD (2). This study, together with SLS1 that compared oral cyclophosphamide to placebo (3), provides a large and wellcharacterized cohort that can be used to assess change in lung function parameters over 12 and 24 months. These two studies have similar study populations, endpoints, and follow up durations, providing a valuable opportunity to integrate patient-level data and perform a combined analysis to address challenging questions.

One of the potential opportunities permitted by such cohorts is estimation of the minimum clinically important difference (MCID), a goal that is particularly relevant in studies that demonstrated an improvement in clinically important outcomes. The MCID is defined as the minimum change in a measurement that can be reliably detected by a patient (4). The MCID term was first introduced into the pulmonary medicine lexicon in 1989 when applied to questionnaires measuring the impact of chronic respiratory disease and congestive heart failure (4). Since this first report, many studies have used both distribution- or anchor-based approaches, and ideally both, to determine MCIDs for multiple outcomes in a variety of pulmonary diseases (5). The distribution-based approach relies on the frequency distribution of a variable and provides an estimation of the magnitude of change that is likely to be statistically, and possibly clinically, significant. The anchor-based approach requires measurement of a second variable that typically has an established MCID and is correlated with the outcome of interest. This association is used to determine the magnitude of change in the outcome of interest that corresponds to the MCID of the second variable. The anchor-based approach can thus link a less important outcome to an important clinical outcome to help explain the clinical implications of change in this less important outcome, an advantage that is particularly helpful for endpoints like the FVC that have limited importance to patients in isolation. The SLS 1 and 2 trials provide an excellent opportunity to determine an anchor-based MCID for FVC because the change in pulmonary function can be anchored to other clinically relevant variables that were recorded in these studies. In this way, Kafaja and colleagues used robust data from two important trials to determine a group level MCID of approximately 3-5\% for FVC in SSc-ILD (6).

One recurring challenge in placebo-controlled SSc-ILD studies has been that the average benefit of therapy on FVC is small, despite being statistically significant $(3,7)$. At first glance, this FVC MCID of $3-5 \%$ is underwhelming as it is less than usual measurement error and this change would not generally be regarded as clinically meaningful. $(8,9)$ However, it is often more helpful to consider the 
MCID as a threshold that can yield a number needed to treat. This type of analysis will be important for ongoing similar clinical trials in diseases like SSc-ILD that can have a widely variable response to therapy. The small MCID in SSc-ILD and relatively slow progression will also make add-on studies such as RECITAL particularly challenging to power (10), but it is notable that one of the most ambitious SSc-ILD studies to date, targeting 520 patients randomised to nintedanib or placebo, and stratified for background immunosuppressive therapy, has recently reached full recruitment (11).

An important caveat is that these findings do not apply to an individual patient in clinical practice, as these are group-level effects derived from large trial populations evaluated as a whole. Individual patient analyses, such as that of Goh et al 2017 (12), are more likely to be useful when evaluating potential treatment effects within a single patient. Another important caveat is that the FVC is not only representing the impact of immunosuppressive therapy on ILD severity, and that there are additional manifestations of SSc-ILD that are in part captured by FVC (e.g., muscle weakness, pleural disease). The immunosuppressive therapies in the SLS-1 and -2 studies may impact both ILD and non-ILD determinants of FVC, suggesting that the MCID now derived from Kafaja et al is not only reflecting the impact of therapy on ILD severity, and is instead measuring the total impact of these therapies on lung function that may occur through multiple mechanisms. These additional determinants of FVC in SSC-ILD are unique compared to many other ILDs that are isolated parenchymal lung disorders, and may explain some of the differences in the MCID of FVC in SSC-ILD compared to other chronic lung diseases $(13,14)$.

The multiple determinants of FVC in SSc-ILD are in some ways desirable as FVC is thus a more complete measure of disease severity that provides a better estimate of a patient's overall wellbeing. Conversely, there are some situations in which one desires a more pure measure of ILD severity. Lung function measurements, including FVC and especially DLCO, are likely imperfect surrogates for this purpose given the likely high noise to signal ratio. This limitation has led to recent efforts to identify other potential endpoints for fibrotic ILD, including both visual and quantitative assessment of ILD severity on computed tomography in SSc and other fibrotic ILDs $(15,16)$. Quantitative imaging is a powerful new tool that is quickly becoming a standard key endpoint in clinical trials for multiple fibrotic ILDs, and this may be a highly advantageous efficacy measure in early-phase proof-of-concept clinical trials. Identifying the MCID for FVC and other endpoints is critical to support use of these novel endpoints by providing clinical context to outcomes that are otherwise of relatively little direct importance to patients.

In conclusion, we can now start to draw on lessons of recent studies to improve understanding of treatment effects in future trials. This is valuable because patients, regulators and payers will want to know whether new and potentially expensive therapies offer clinical benefit, an acceptable risk: benefit profile, and value for money. This paper reminds us that clinical trials can generate much additional information beyond the primary analysis and that such data should be fully available and utilized from both commercial and academic studies. However, it is also important that conclusions based upon group level data and estimates of MCID are applied with caution to individual patients when making treatment or funding decisions, and to ensure that trial-derived metrics do not become a barrier to access when striving for cost-effective and evidence-based treatment of uncommon life-threatening diseases with few management options. 


\section{References}

1. Seibold JR, Denton CP, Furst DE, Guillevin L, Rubin LJ, Wells A, Matucci Cerinic M, Riemekasten G, Emery P, Chadha-Boreham H, Charef P, Roux S, Black CM. Randomized, prospective, placebo-controlled trial of bosentan in interstitial lung disease secondary to systemic sclerosis. Arthritis Rheum 2010; 62: 2101-2108.

2. Tashkin DP, Roth MD, Clements PJ, Furst DE, Khanna D, Kleerup EC, Goldin J, Arriola E, Volkmann ER, Kafaja S, Silver R, Steen V, Strange C, Wise R, Wigley F, Mayes M, Riley DJ, Hussain S, Assassi S, Hsu VM, Patel B, Phillips K, Martinez F, Golden J, Connolly MK, Varga J, Dematte J, Hinchcliff ME, Fischer A, Swigris J, Meehan R, Theodore A, Simms R, Volkov S, Schraufnagel DE, Scholand MB, Frech T, Molitor JA, Highland K, Read CA, Fritzler MJ, Kim GHJ, Tseng CH, Elashoff RM, Sclerodema Lung Study III. Mycophenolate mofetil versus oral cyclophosphamide in scleroderma-related interstitial lung disease (SLS II): a randomised controlled, double-blind, parallel group trial. The lancet Respiratory medicine 2016; 4: 708719.

3. Tashkin DP, Elashoff R, Clements PJ, Goldin J, Roth MD, Furst DE, Arriola E, Silver R, Strange C, Bolster M, Seibold JR, Riley DJ, Hsu VM, Varga J, Schraufnagel DE, Theodore A, Simms R, Wise R, Wigley F, White B, Steen V, Read C, Mayes M, Parsley E, Mubarak K, Connolly MK, Golden J, Olman M, Fessler B, Rothfield N, Metersky M, Scleroderma Lung Study Research G. Cyclophosphamide versus placebo in scleroderma lung disease. New England Journal of Medicine 2006; 354: 2655-2666.

4. Jaeschke R, Singer J, Guyatt GH. Measurement of health status. Ascertaining the minimal clinically important difference. Control Clin Trials 1989; 10: 407-415.

5. Jones PW, Beeh KM, Chapman KR, Decramer M, Mahler DA, Wedzicha JA. Minimal clinically important differences in pharmacological trials. Am J Respir Crit Care Med 2014; 189: 250255.

6. al Ke. Reliability and minimal clinically important differences of forced vital capacity: Results from the Scleroderma Lung Studies (SLS-I and SLS-II).

7. Hoyles RK, Ellis RW, Wellsbury J, Lees B, Newlands P, Goh NS, Roberts C, Desai S, Herrick AL, McHugh NJ, Foley NM, Pearson SB, Emery P, Veale DJ, Denton CP, Wells AU, Black CM, du Bois RM. A multicenter, prospective, randomized, double-blind, placebo-controlled trial of corticosteroids and intravenous cyclophosphamide followed by oral azathioprine for the treatment of pulmonary fibrosis in scleroderma. Arthritis Rheum 2006; 54: 3962-3970.

8. Miller MR, Hankinson J, Brusasco V, Burgos F, Casaburi R, Coates A, Crapo R, Enright P, van der Grinten CP, Gustafsson P, Jensen R, Johnson DC, MacIntyre N, McKay R, Navajas D, Pedersen OF, Pellegrino R, Viegi G, Wanger J. Standardisation of spirometry. Eur Respir J 2005; 26: 319-338.

9. Pellegrino R, Viegi G, Brusasco V, Crapo RO, Burgos F, Casaburi R, Coates A, van der Grinten CP, Gustafsson P, Hankinson J, Jensen R, Johnson DC, Maclntyre N, McKay R, Miller MR, Navajas D, Pedersen OF, Wanger J. Interpretative strategies for lung function tests. Eur Respir J 2005; 26: 948-968.

10. Saunders P, Tsipouri V, Keir GJ, Ashby D, Flather MD, Parfrey H, Babalis D, Renzoni EA, Denton $\mathrm{CP}$, Wells AU, Maher TM. Rituximab versus cyclophosphamide for the treatment of connective tissue disease-associated interstitial lung disease (RECITAL): study protocol for a randomised controlled trial. Trials 2017; 18: 275.

11. Distler O, Brown KK, Distler JHW, Assassi S, Maher TM, Cottin V, Varga J, Coeck C, Gahlemann M, Sauter W, Schmidt H, Highland KB, investigators St. Design of a randomised, placebocontrolled clinical trial of nintedanib in patients with systemic sclerosis-associated interstitial lung disease (SENSCIS). Clin Exp Rheumatol 2017; 35 Suppl 106: 75-81. 
12. Goh NS, Hoyles RK, Denton CP, Hansell DM, Renzoni EA, Maher TM, Nicholson AG, Wells AU. Short-Term Pulmonary Function Trends Are Predictive of Mortality in Interstitial Lung Disease Associated With Systemic Sclerosis. Arthritis Rheumatol 2017; 69: 1670-1678.

13. du Bois RM, Weycker D, Albera C, Bradford WZ, Costabel U, Kartashov A, King TE, Jr., Lancaster L, Noble PW, Sahn SA, Thomeer M, Valeyre D, Wells AU. Forced vital capacity in patients with idiopathic pulmonary fibrosis: test properties and minimal clinically important difference. Am J Respir Crit Care Med 2011; 184: 1382-1389.

14. Patel AS, Siegert RJ, Keir GJ, Bajwah S, Barker RD, Maher TM, Renzoni EA, Wells AU, Higginson IJ, Birring SS. The minimal important difference of the King's Brief Interstitial Lung Disease Questionnaire (K-BILD) and forced vital capacity in interstitial lung disease. Respir Med 2013; 107: 1438-1443.

15. Kim HJ, Brown MS, Elashoff R, Li G, Gjertson DW, Lynch DA, Strollo DC, Kleerup E, Chong D, Shah SK, Ahmad S, Abtin F, Tashkin DP, Goldin JG. Quantitative texture-based assessment of oneyear changes in fibrotic reticular patterns on HRCT in scleroderma lung disease treated with oral cyclophosphamide. European radiology 2011; 21: 2455-2465.

16. Goldin J, Elashoff R, Kim HJ, Yan X, Lynch D, Strollo D, Roth MD, Clements P, Furst DE, Khanna D, Vasunilashorn S, Li G, Tashkin DP. Treatment of scleroderma-interstitial lung disease with cyclophosphamide is associated with less progressive fibrosis on serial thoracic highresolution CT scan than placebo: findings from the scleroderma lung study. Chest 2009; 136: 1333-1340. 